\title{
A Kind of Analytic Hierarchy Process and Neural Network Integrated Evaluation Method of Teaching
}

\author{
Hongjun Yang ${ }^{\mathrm{a}}$, Juanjuan $\mathrm{Xu}$ \\ School of Manzhouli, Inner Mongolia University, Man Zhou Li, 021400, China; \\ ayhj301456@163.com, bhx8608@126.com
}

Keywords: Teaching evaluation, AHP, BP neural network, preference coefficient

\begin{abstract}
Teaching evaluation as the core content of teaching management, it plays a very important role in the process of teaching. In terms of evaluation method, AHP can make full use of expert opinions, but it's hard to get rid of the randomness in the process of decision making, subjective uncertainty and vagueness of the understanding; is not affected by man-made factors of neural network evaluation but can't reflect the preference. So this paper puts forward AHP and neural network combining the teaching evaluation of the new model, using AHP and neural network to performance evaluation indexes, the introduction of subjective and objective preference coefficient, using the weighted method to determine the criterion of comprehensive weight. Results show that the model based on AHP and neural network compared with the existing teaching evaluation method is more accurate, and it can provide for teaching management reference.
\end{abstract}

\section{Introduction}

In recent years, a large number of researchers have done deep research in the field of teaching evaluation. From these studies [1-2], we found that almost all of the teaching evaluation method provides a good mathematical model, but these studies are not fully considered to design a scientific and objective evaluation index system. It is difficult to get rid of randomness in the process of decision-making and eligible people's subjective uncertainty. In fact, the key to these problems is how to be more objective, accurate determination of teaching evaluation index weight. Teaching evaluation problem belongs to a kind of multiple attribute decision making problems, influencing factors, and importance is different, so the whole evaluation system a non-linear relationship. Learned from many documents [3-5], neural network theory is a good way to deal with complex nonlinear problems, eliminate human factors and the main factors in the decision-making process. Meanwhile, the analytic hierarchy process is put forward, can guarantee the effectiveness of the quantitative analysis. In this paper, in order to better solve the teaching evaluation of qualitative colour problems, proposed neural network and hierarchical analysis method of teaching evaluation model. In particular, By using analytic hierarchy process and neural network to performance evaluation indexes, the introduction of subjective and objective preference coefficient, using the weighted method determine the comprehensive weights of criteria, so that the teaching evaluation more accurate and objective.

\section{Establishing the teaching performance evaluation index system}

It is necessary to design the evaluation index system from different angles and levels for revealing the teaching performance accurately. Teaching evaluation is based on the teaching goal of teaching process and the result of value judgment and decision service for the teaching activity, is the reality of teaching activities or potential value of the process of judgment. Generally includes teachers, students in the teaching process, teaching contents, teaching methods, and teaching management and so on.

To make the teaching evaluation more scientific and reasonable, to improve the quality of teaching, the purpose of improving teaching work, this paper combined with the experience of experts and scholars, in as much as possible to keep the evaluation index system on the basis of complete, according to the teaching evaluation is scientific, dynamic and practical principles, The hierarchical structure was achieved, as shown in Table 1. It consists of five factors: "teaching attitude", "communication and 
interaction”, “teaching for learning”, "teaching links”, “teaching methods”, "teaching contents” and "teaching effect", each of which is divided into two or more sub-factors[6].

Table1. The teaching performance hierarchical structure.

\begin{tabular}{|c|c|}
\hline main factors & Sub-factors \\
\hline Teaching attitude(C1) & $\begin{array}{l}\text { a teacher by worthy example, teach by personal example as well as verbal instruction } \\
\text { Strictly abide by the order of teaching (X2) } \\
\text { Teaching in high spirit, enthusiasm and attractive (X3) }\end{array}$ \\
\hline Teaching link(C2) & $\begin{array}{l}\text { Preparation before class, teaching plan writing seriously (X4) } \\
\text { Homework quality, pay attention to answering questions after class (X5) } \\
\text { Can master the use of teaching tools (X6) }\end{array}$ \\
\hline Teaching content(C3) & $\begin{array}{l}\text { Teaching content mastery, application freely }(X 7) \\
\text { Is rich in content, full of information, the difficulty to control properly (X8) } \\
\text { Theory with practice, accurately reflect academic frontiers and new achievements (X9) } \\
\text { Teaching material to choose appropriate (X10) }\end{array}$ \\
\hline Teaching effect(C4) & $\begin{array}{l}\text { Explaining thorough, the student can accept in a timely manner (X11) } \\
\text { By learning something, open up the mind (X12) }\end{array}$ \\
\hline Teaching method(C5) & $\begin{array}{l}\text { Good to mobilize students' learning atmosphere (X13) } \\
\text { Inspire students to think actively, and to cultivate the innovative ability (X14) }\end{array}$ \\
\hline
\end{tabular}

\section{Based on the AHP teaching evaluation matrix and weight calculation}

\subsection{Based on the AHP teaching evaluation matrix and weight calculation}

AHP is a multi-criteria decision making method, using the combination of qualitative analysis and quantitative analysis. Teaching evaluation index system defines the hierarchical structure, making it easy to use AHP method to determine the index weight, and eventually received a teaching evaluation results. According to the teaching evaluation index in table 1 and the results of the expert questionnaire, compare the importance of the elements of all levels, and gives a primary index corresponds to the secondary indexes of judgment matrix.

1): The hierarchical structure of the teaching evaluation index is divided into two layers, the first layer five factors: $C=\left\{C_{1}, C_{2}, C_{3}, C_{4}, C_{5}\right\}$, the second layer 14 factors:

$C 1=\left\{X_{1}, X_{2}, X_{3}\right\}, C 2=\left\{X_{4}, X_{5}, X_{6}, X_{7}\right\}, C 3=\left\{X_{8}, X_{9}, X_{10}\right\}, C 4=\left\{X_{11}, X_{12}\right\}, C 5=\left\{X_{13}, X_{14}\right\}$.

2): Determine judgment matrix. $C$ as the first level of judgment matrix , $C_{i}$ as the second level of judgment matrix: $\mathrm{C}=[1,2,2,0.25,1 ; 0.5,1,1,0.25,0.5 ; 0.5,1,1,0.5,0.5 ; 4,4,2,1,1 ; 1,2,2,1,1]$, $\mathrm{C} 1=[1,1,0.5 ; 1,1,1 ; 2,1,1], \mathrm{C} 2=[1,1 / 3,1,1 ; 3,1,3,1 ; 1,1 / 3,1,1 ; 1,1 / 3,1,1]$, $\mathrm{C} 3=[1,1,2,2 ; 1,1,2,1 ; 0.5,0.5,1,1 ; 0.5,1,1,1], \mathrm{C} 4=[1,1 ; 1,1], \mathrm{C} 5=[1,1 / 2 ; 2,1]$.

$3)$ : Using the characteristic root method for solving weights vector:

$$
\begin{aligned}
& w=\left(\begin{array}{lllll}
0.1791 & 0.0985 & 0.1164 & 0.3734 & 0.2327
\end{array}\right)^{T} . \\
& w_{1}=\left(\begin{array}{llll}
0.2599 & 0.3275 & 0.4126
\end{array}\right)^{T}, w_{2}=\left(\begin{array}{llll}
0.2000 & 0.6000 & 0.2000
\end{array}\right)^{T} \text {, } \\
& w_{3}=\left(\begin{array}{llll}
0.3088 & 0.3430 & 0.1544 & 0.1937
\end{array}\right)^{T}, w_{4}=\left(\begin{array}{lll}
0.5 & 0.5
\end{array}\right)^{T} w_{5}=\left(\begin{array}{lll}
0.3333 & 0.6666
\end{array}\right)^{T} \text {. }
\end{aligned}
$$

4): Hierarchy total sorts: $w^{\prime}=\left(\begin{array}{l}0.047,0.059,0.074,0.019,0.059,0.019,0.035 \\ 0.039,0.017,0.022,0.186,0.186,0.077,0.155\end{array}\right)$.

5): Consistency checking, as shown in table 2.

Table2. consistency checking

\begin{tabular}{ccccccc}
\hline consistency & C & C1 & C2 & C3 & C4 & C5 \\
\hline$\lambda_{\max }$ & 5.220 & 3.053 & 3.000 & 4.365 & 3.018 & 3.053 \\
C.R. & 0.049 & 0.046 & 0 & 0.026 & - & - \\
\hline
\end{tabular}

\subsection{Teaching evaluation based on BP neural network}

\subsubsection{Mathematical model}

As an effective tool for the study of complex problems, the BP-NN has been widely used in many fields, such as extreme value optimization, classification, target recognition etc. The emergence of neural network, as well as the teaching evaluation provides a new evaluation method.

Teaching quality evaluation is the use of education evaluation theory and technology in the teaching process and its result is reached a certain quality requirements of value judgment, the purpose is to 
improve the teaching quality enhances unceasingly. Teaching is a dynamic process of teaching and learning, there are many factors affecting the quality of teaching, and the factors influence is also different, lead to the quality of teaching presents complex nonlinear relationship, it is difficult to set up with a reasonable and precise mathematical analytical formula. Assuming that the teaching quality evaluation index for $X=\left\{x_{1}, x_{2}, \cdots x_{n}\right\}$, then the mathematical model of teaching quality evaluation can be expressed as $y=f(X)$. Its essence is to find one of the most adaptive $f(X)$, make its can well represent the teaching evaluation system of the nonlinear relationship. Teaching evaluation mathematical model of the structure is shown in figure 1.

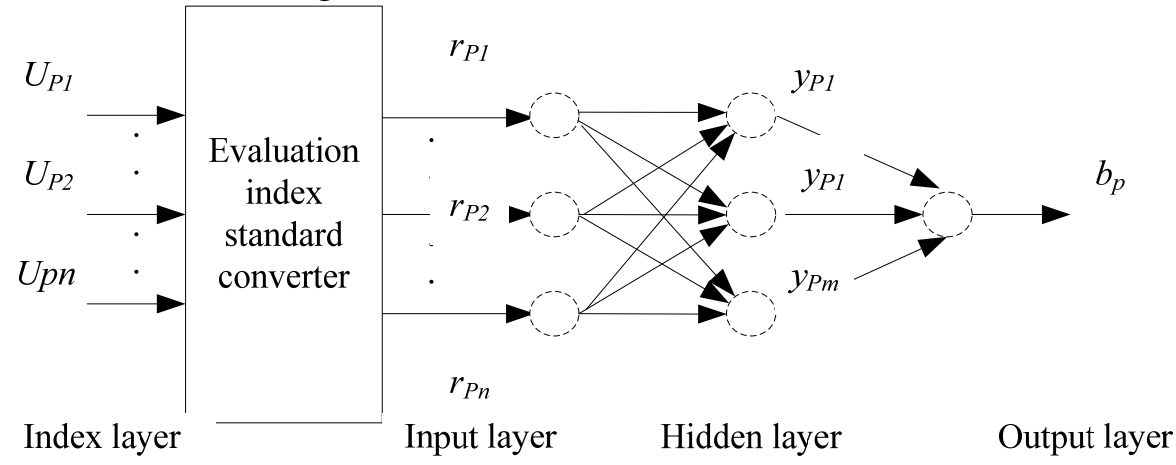

Figure 1 Mathematical model of teaching evaluation

In figure $1, U_{P 1}, U_{P 2}, \cdots, U_{P n}$ for the first $\mathrm{n}$ samples of evaluation indexes, Namely: $\overline{U_{P}}=$ $\left\{U_{P 1}, U_{P 2} \cdots U_{P n}\right\}$.Evaluation vector $\mathrm{r}_{P 1}, r_{P 2} \cdots r_{P n}$ is obtained by $U_{P}$ get after quantitative index standardization converter, $\overline{r_{P}}=\left\{\mathrm{r}_{P 1}, r_{P 2} \cdots r_{P n}\right\}$. The output of the sample pattern $\mathrm{p}$ is $b_{p}$.

3.2.2 Data preprocessing

According to the data in table 1 and teaching quality survey analysis table, firstly through the form of questionnaire survey, a total of 2500 questionnaires distributed, Each teacher have 50 copies of the same questionnaire, and to select 50 teachers as evaluated objects, Then from all students randomly selected 40 people to score the questionnaire, and select 10 experts has scored the questionnaire after class, The scope of the evaluation index as the [0,10], Students and experts for many times after class to get the results as comprehensive score values, the part of the data as shown in table 3.

Table3. Teaching quality evaluation.

\begin{tabular}{|c|c|c|c|c|c|c|c|c|c|}
\hline \multirow{2}{*}{ Sample no. } & \multicolumn{8}{|c|}{ The secondary evaluation index } & \multirow{2}{*}{ evaluation results } \\
\hline & $X_{1}$ & $\mathrm{X}_{2}$ & $\mathrm{X}_{3}$ & $\mathrm{X}_{4}$ & $\mathrm{X}_{5}$ & $\mathrm{X}_{6}$ & $\ldots$ & $\mathrm{X}_{14}$ & \\
\hline 1 & 5.6 & 7.5 & 6.5 & 9.9 & 8.9 & 8.3 & $\cdots$ & 4.3 & 7.2 \\
\hline 2 & 9.1 & 9.4 & 8.3 & 8.3 & 4.2 & 5.7 & $\ldots$ & 9.0 & 7.5 \\
\hline 3 & 8.5 & 4.1 & 8.2 & 9.9 & 6.5 & 6.0 & ... & 7.1 & 5.9 \\
\hline 4 & 6.3 & 8.0 & 8.8 & 4.6 & 10.0 & 9.7 & $\cdots$ & 5.6 & 6.5 \\
\hline 5 & 8.7 & 7.0 & 4.1 & 6.7 & 5.5 & 7.0 & $\cdots$ & 4.6 & 6.3 \\
\hline$\ldots$ & $\ldots$ & $\ldots$ & $\ldots$ & $\ldots$ & $\ldots$ & $\ldots$ & $\ldots$ & $\ldots$ & $\ldots$ \\
\hline 50 & 6.2 & 9.7 & 6.8 & 4.1 & 8.2 & 5.8 & $\ldots$ & 9.6 & 6.6 \\
\hline
\end{tabular}

From 50 college teachers randomly selected 40 as neural network training, 10 as the neural network performance test. Before evaluation, the indexes should be standardized processing variables, which must take each evaluation index by some kind of membership function will be normalized to within the scope of $[0,1]$. Then the processed data as training samples of BP neural network and prediction index.

3.2.3 Neural network teaching evaluation algorithm

Teaching evaluation based on BP algorithm steps are as follows:

Step1: Give a comprehensive evaluation model of BP network structure parameters. Assuming that evaluation index theory domain $X=\left\{x_{1}, x_{2}, \cdots x_{14}\right\}$, Choose the input node number is 14 ; the number of hidden layer nodes is 8 ; the output node number is 1 .

Step2: A given connection weights and threshold of neurons initialization.

Step3: Randomly selected 40 teachers' teaching evaluation index as the training of the neural network training samples, the matrix of the input indicators $\left[U_{P j}\right]_{(40 \times 14)}$, and the comprehensive evaluation of the results as expected output. $B=\left(x_{1}, x_{2}, \cdots x_{40}\right)^{T}$. 
Step4: $x_{j}(j=1,2, \ldots 14)$ normalization processing, $\left[U_{-} P j\right]_{-}(40 \times 14) \Rightarrow R=\left[r_{-} P j\right]_{-}(40 \times 14)$.

Step5: Neural network training, Based on the assumption that there is nonlinear mapping relationship between $\mathrm{R}$ and $\mathrm{B}, b_{p}=F\left(\overline{r_{P}}\right), p=1,2 \cdots 40, \overline{r_{P}}=\left(r_{p 1}, r_{p 2}, \cdots r_{p 40}\right)$.

Step6: After continuously perform the iterative process, until meet epsilon setting error $\varepsilon=10^{-4}$, you can get more accurate internal representation of the nonlinear mapping relation. The part of the connection weights $w_{i j}$ and $v_{j}$ as shown in table 4.

Table4. Part of the connection weight value table.

\begin{tabular}{cccccccccccc}
\hline \multirow{2}{*}{ Hidden layer } & \multicolumn{1}{c}{ The input layer unit } \\
& 1 & 2 & 3 & 4 & 5 & 6 & 7 & $\cdots$ & 13 & 14 & Output layer \\
\hline 1 & -0.089 & -0.141 & 0.882 & 0.264 & 0.313 & 0.035 & -0.597 & $\cdots$ & 0.253 & 0.179 & 0.153 \\
2 & -0.890 & -0.338 & -0.364 & -0.010 & 0.276 & 0.548 & 0.034 & $\cdots$ & -0.699 & 0.478 & -0.170 \\
3 & 0.053 & -0.048 & -0.369 & 0.052 & -0.531 & -0.294 & -0.228 & $\cdots$ & -0.098 & -0.940 & -0.499 \\
4 & -0.452 & -0.685 & 0.496 & 0.033 & 0.530 & 0.423 & 0.572 & $\cdots$ & 0.164 & -0.528 & -0.158 \\
5 & -0.052 & 0.105 & -0.408 & -0.345 & -0.954 & 0.030 & 0.041 & $\cdots$ & -0.550 & 0.026 & -0.311 \\
6 & 0.300 & 0.630 & 0.577 & -0.597 & 0.493 & 0.387 & 0.086 & $\cdots$ & 0.036 & 0.297 & -0.113 \\
7 & 0.278 & -0.512 & -0.600 & 0.311 & 0.223 & 0.262 & -0.709 & $\cdots$ & 0.487 & -0.304 & -0.380 \\
8 & 0.091 & -0.428 & -0.188 & -0.269 & -0.434 & -0.388 & -0.125 & $\cdots$ & 0.570 & 0.597 & 0.426 \\
\hline
\end{tabular}

3.2.4 Neural network teaching evaluation weight calculation

Establish neural network learning algorithm aims to determine the weights of evaluation indexes, and the results of neural network training is the relationship between the neurons in the neural network, to get the real relationship between input factors relative to the output, which is input to output factors decision weights, also need to the weight of each neurons analysis processing, therefore using the following formula to describe the relationship between the input and output factors.

$$
\varphi_{i}=\sum_{j=1}^{L}\left(W_{i j} V_{j}\right) / \sum_{i=1}^{N} \sum_{j=1}^{L}\left|W_{i j} V_{j}\right|
$$

Calculated by the data from table 3 and type 1 , it is concluded that the weight of each evaluation index vector is: $\varphi=\left(\begin{array}{l}0.045,0.063,0.071,0.022,0.057,0.018,0.037 \\ 0.041,0.015,0.024,0.183,0.183,0.081,0.158\end{array}\right)$.

\subsection{Comprehensive weighting}

AHP reflect the subjective preferences of decision makers, Neural network reflects the objective existence of the relationship between attribute values, in order to seek the criteria weight comprehensive reflection of the relationship between the subjective and objective, fully embodies the advantages of AHP-BP, the linear weighted method is given by using the index of the comprehensive weight:

$$
w^{*}=\alpha w^{\prime}+(1-\alpha) \varphi
$$

In Type 2, $w^{*}$ as comprehensive weight; $w^{\prime}$ as the weight is got by hierarchical analysis method; $\varphi$ for neural network evaluation method is used to get the weight; $\alpha$ coefficient for subjective preference; $1-\alpha$ coefficient for objective preference, $\alpha \in[0,1] . \alpha$ specific values given by according to preference. Especially when $\alpha=0, w^{*}$ is calculated through the neural network weights, when the $\alpha=1, w^{*}$ as the weight of the analytic hierarchy process.

\section{Results compared with other methods of teaching evaluation}

In order to further show the superiority of evaluation AHP-BPNN model, Choose the expert evaluation method, AHP, BP-NN to contrast experiment, the evaluation results and the relative error as a measure of the model, Comparing selected 10 evaluation objects, and the result as shown in table 5 .

In table 5 different evaluation method and expert evaluation result, it can be seen that based on the AHP evaluation result of the average relative error is $4.715 \%$, the average relative error of evaluation result based on BPNN is $2.966 \%$, based on the AHP evaluation result of the average relative error was $0.767 \%$. So can get the following conclusion:

(1) The evaluation results of BP is superior to the AHP evaluation result, it is mainly due to the neural network has the independent learning ability, can well reflect the teaching quality evaluation index and nonlinear relation between evaluation results and reduce the influence of artificial factors. 
(2) The combination of AHP-BPNN empowerment evaluation precision is highest, that of the evaluation index by AHP analysis, ensure the combination of qualitative analysis and quantitative analysis, and the BP neural network has higher adaptive and self-learning ability, overcome by the randomness of artificial evaluation caused by human factors and eligible persons subjective uncertainty and fuzziness of knowledge, so as to ensure the objectivity and accuracy of evaluation results.

Table5. Contrast experiment analysis.

\begin{tabular}{|c|c|c|c|c|c|c|c|}
\hline \multirow[b]{2}{*}{$\begin{array}{c}\text { Evaluation } \\
\text { object }\end{array}$} & \multirow{2}{*}{$\begin{array}{c}\text { Expert } \\
\text { evaluation } \\
\text { results }\end{array}$} & \multicolumn{2}{|c|}{ AHP } & \multicolumn{2}{|c|}{ BPNN } & \multicolumn{2}{|c|}{ AHP-BP } \\
\hline & & $\begin{array}{c}\text { Evaluation } \\
\text { results }\end{array}$ & $\begin{array}{c}\text { Relative } \\
\text { error }\end{array}$ & $\begin{array}{l}\text { Evaluation } \\
\text { results }\end{array}$ & $\begin{array}{c}\text { Relative } \\
\text { error }\end{array}$ & $\begin{array}{c}\text { Evaluation } \\
\text { results }\end{array}$ & $\begin{array}{c}\text { Relative } \\
\text { error }\end{array}$ \\
\hline 1 & 5.6 & 5.120 & $-8.571 \%$ & 5.321 & $-4.982 \%$ & 5.521 & $-1.411 \%$ \\
\hline 2 & 6.8 & 6.533 & $-3.926 \%$ & 6.753 & $-0.691 \%$ & 6.833 & $0.485 \%$ \\
\hline 3 & 6.2 & 6.036 & $-2.645 \%$ & 6.148 & $-0.839 \%$ & 6.211 & $0.177 \%$ \\
\hline 4 & 6.0 & 5.659 & $-5.683 \%$ & 5.881 & $-1.983 \%$ & 6.009 & $0.150 \%$ \\
\hline 5 & 7.6 & 7.192 & $-5.368 \%$ & 7.456 & $-1.895 \%$ & 7.592 & $-0.105 \%$ \\
\hline 6 & 6.6 & 7.107 & $7.682 \%$ & 6.308 & $-4.424 \%$ & 6.507 & $-1.409 \%$ \\
\hline 7 & 6.2 & 5.672 & $-8.516 \%$ & 5.972 & $-3.677 \%$ & 6.123 & $-1.242 \%$ \\
\hline 8 & 5.8 & 5.586 & $-3.690 \%$ & 5.700 & $-1.724 \%$ & 5.786 & $-0.241 \%$ \\
\hline 9 & 6.1 & 5.356 & $-12.197 \%$ & 5.654 & $-7.311 \%$ & 5.885 & $-3.525 \%$ \\
\hline 10 & 6.7 & 6.416 & $-4.239 \%$ & 6.557 & $-2.134 \%$ & 6.663 & $-0.552 \%$ \\
\hline
\end{tabular}

\section{Conclusion}

The teaching evaluation model based on AHP and neural network, using AHP and neural network to performance evaluation index, the introduction of subjective and objective preference coefficient, determine standards using the method of weighted comprehensive weight. So this model not only can be importance for evaluation index selection, can also give attention to both the subjective and objective empowerment, thus reducing human error evaluation process; At the same time also can avoid the traditional evaluation process need to establish a mathematical model of the complex as well as the analytical solution of mathematics problems. The results show that the model based on AHP-BPNN evaluation results more accurate and reliable, fault tolerant ability is stronger. It may also be used as a reference for management practitioners when solving decision-making problems.

\section{References}

[1] Ory, J. C. (2000). Teaching evaluation: Past, present, and future. New directions for teaching and learning, 2000(83), 13-18.

[2] Lin, H.-F. (2010). An application of fuzzy AHP for evaluating course website quality. Computers \& Education, 54(4), 877-888.

[3] Kuo, R. J., Chi, S.-C. (2002). A decision support system for selecting convenience store location through integration of fuzzy AHP and artificial neural network. Computers in Industry, 47(2), 199-214.

[4] Xuhui, W., \& Feihua, H. (2007). The Model of Teaching Quality Evaluation Based on BP Neural Networks and Its Application [J]. Research in Higher Education of Engineering, 5, 78-81.

[5] Yazgan, H. R. (2009). An ERP software selection process with using artificial neural network based on analytic network process approach. Expert Systems with Applications, 36(5), 9214-9222.

[6] Brooker, R., Muller, R., Mylonas, A. (1998). Improving the assessment of practice teaching: a criteria and standards framework. Assessment and Evaluation in Higher Education, 23(1), 5-24. 